\title{
Thoracic epidural hematoma
}

\author{
Alessandro De Cassai (D) \\ Received: 2 November 2018/Revised: 10 November 2018/Accepted: 26 November 2018/Published online: 4 December 2018 \\ (C) Canadian Anesthesiologists' Society 2018
}

A 74-year-old male underwent laparotomy for colorectal cancer; apart from ramipril $2.5 \mathrm{mg}$ to treat hypertension, he was receiving no anti-platelet therapy or other anticoagulants. His preoperative laboratory investigations included an international normalized ratio (INR) of 1.09, a partial thromboplastin time (PTT) of $28 \mathrm{sec}$, and a platelet count (PLT) of $259 \times 10^{9} \cdot \mathrm{L}^{-1}$. A thoracic epidural catheter for postoperative analgesia was inserted preoperatively on the first attempt $3 \mathrm{~cm}$ into the T9-T10 epidural space using an 18G Touhy needle. The operation was uneventful with no apparent complications during the first four postoperative days. The epidural catheter was removed on the fourth postoperative day; coagulation parameters were normal at that time (INR, 1.19; PTT $28 \mathrm{sec}$; PLT 289 $\mathrm{x} 10^{9} \cdot \mathrm{L}^{-1}$ ) and low molecular weight heparin (enoxaparin $4000 \mathrm{UI} /$ once daily) had been administered $13 \mathrm{hr}$ earlier. On the fifth postoperative evening, the patient developed acute severe back pain with progressive weakness progressing to paraplegia. Magnetic resonance imaging showed an $80 \mathrm{~mm}$ x $20 \mathrm{~mm}$ epidural hematoma at the T8T10 level causing spinal cord compression. The patient underwent an emergent decompressive laminectomy and made a full recovery without neurologic sequalae.

Epidural hematomas are a rare but catastrophic complication of neuraxial anesthesia. The incidence of epidural hematomas varies from 1:3600 for patients undergoing knee arthroplasty to 1:200,000 in women undergoing obstetrical procedures. ${ }^{1}$ They are most often seen in settings of abnormal coagulation, challenging anatomy, and multiple attempts at needle/catheter

\footnotetext{
A. De Cassai $(\square)$

Department of Medicine, Section of Anaesthesiology and Intensive Care, University of Padua, Padua, Italy

e-mail: alessandro.decassai@gmail.com
}

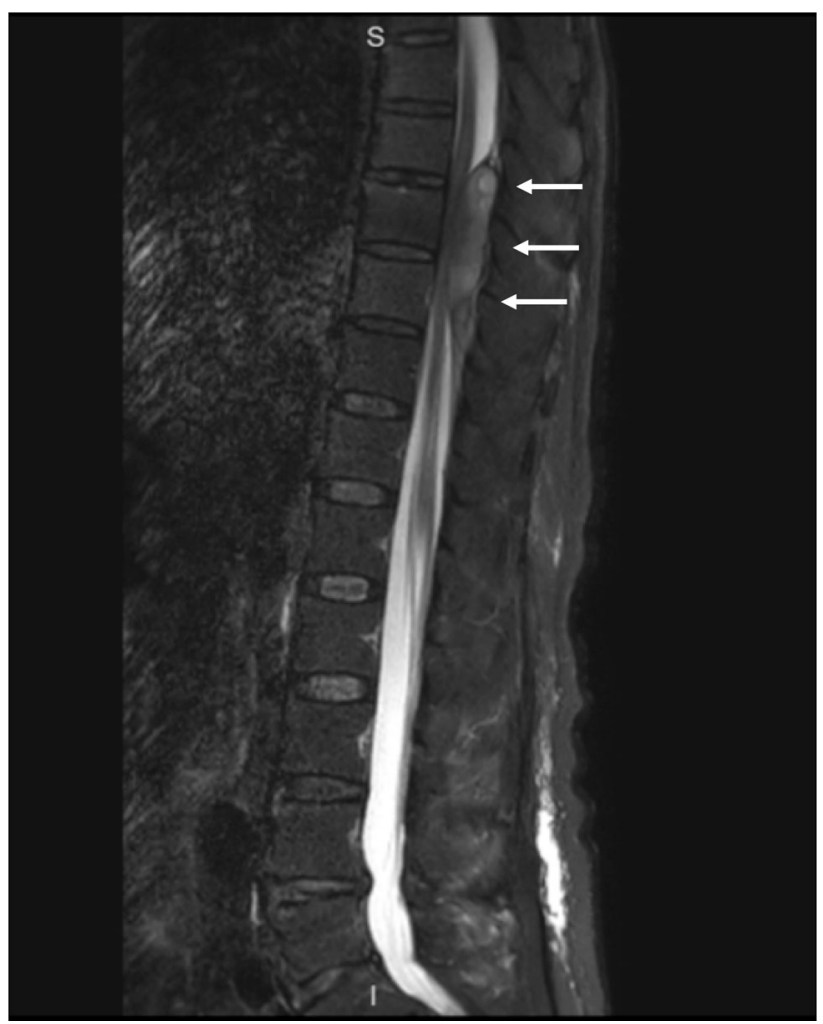

Figure A magnetic resonance image showing a T8-T10 epidural hematoma (white arrows) compressing the spinal cord that presented on the fifth postoperative day following removal of an epidural catheter. The hematoma is seen as a hyperintense and heterogeneous signal by $\mathrm{T} 2$ imaging; parasagittal and sagittal images usually show a lesion with a convex lens shape

insertion. ${ }^{1}$ Nevertheless, these complications can also occur when no risk factors are identified. Importantly, this bleeding complication can also occur after catheter removal. Neuraxial hematoma symptoms vary depending on the level of the lesion, but often present with the acute onset of severe back pain along with sensory changes, weakness, and incontinence. Urgent decompressive surgery is highly recommended to reduce the long-term neurologic sequelae. $^{2}$ 
Conflicts of interest None declared.

Editorial responsibility This submission was handled by Dr. Hilary P. Grocott, Editor-in-Chief, Canadian Journal of Anesthesia.

Funding Support was provided solely from institutional and/or departmental sources.

\section{References}

1. Neal JM, Barrington MJ, Brull R, et al. The second ASRA practice advisory on neurologic complications associated with regional anesthesia and pain medicine: executive summary 2015. Reg Anesth Pain Med 2015; 40: 401-30.

2. Lawton MT, Porter RW, Hiserman JE, Jacobowitz R, Sonntag VH, Dickman $C A$. Surgical management of spinal epidural hematoma: relationship between surgical timing and neurological outcome. J Neurosurg 1995; 83: 1-7. 